\title{
The Impact of Different Aggregate Types and Its Composition on Resulting Concrete Properties Representing the Water Impermeability Level of Concrete for the Construction of White Boxes
}

\author{
Lucia Osuská ${ }^{1,2, *}$, Rudolf Hela ${ }^{1,2}$ \\ ${ }^{1}$ Faculty of Civil Engineering, Brno University of Technology, Institute of Technology, Czech Republic \\ ${ }^{2}$ Institute of Building Materials and Technology, Czech Republic
}

Received November 25, 2019; Revised February 1, 2020; Accepted February 7, 2020

Copyright $\odot 2020$ by authors, all rights reserved. Authors agree that this article remains permanently open access under the terms of the Creative Commons Attribution License 4.0 International License

\begin{abstract}
We understand the term 'white box' as a concrete structure in underground spaces, basements, or cellars, where it is necessary to consider the water impermeability of concrete or minimal changes in volume changes of concrete. These properties can be attained by creating the maximal compactness of the concrete composite when using the optimal combination of entrance components. The goal of this article is mainly to verify the effects of aggregate variety and its granulometric curve during the observation of volume changes and the water impermeability of concrete and another property, which are in white boxes constructions important. Granulometric curves of aggregates will be designed to ensure the minimal voids content of an aggregate, and the effect of the discontinuous granulometric curve will also be observed with respect of this property. During the design of the concrete mixtures, account was taken of a high amount of binding agent, which is used ensuring the higher compactness of cement stone was considered besides. For this reason, it will be verified also additive of finely ground limestone, thanks to which it is possible to partially replace a part of cement while maintaining the same properties of concrete. This method of design can lead not only to positive elimination of volume changes in a concrete mixture but also has a significant impact on dried concrete parameters, such as a high level of water impermeability.
\end{abstract}

Keywords Impermeable Concrete, Volume Changes, Granulometric Curve, Cavern Concrete

\section{Introduction}

The so-called 'white box' is a frequently sought alternative to secondary protective coats or various hydro-insulation systems during the construction of the foundations of buildings or underground building with the predicted occurrence of groundwater under pressure. These structures are a suitable solution during the construction of underground parts of residential or public buildings, cellars, family houses, or buildings in general because they show property of high water impermeability. 'White box' is a term for reinforced concrete that has a hydro-insulation function, besides the structural function, without the need for using standard insulations. The hydro-insulation feature of a functional white box is ensured by several factors, such as correct construction and flawless design, but it is also appropriate for designing the composition of a concrete mixture. [1,2] For this impermeability concrete, it is necessary to have properties like low water absorption, high resistance to the penetration of groundwater under pressure, and minimal volume changes. It is well known that cement-based construction material is subject to various types of deformations, even in early stages. In terms of deformations that are not caused by mechanical activity, it is especially concrete shrinkage because of hydration processes. In the case of white box construction, cracks caused by shrinkage can significantly decrease the lifetime of such a construction; thus, it is necessary to approach concrete design in such a manner to reach the lowest possible shrinkage. 


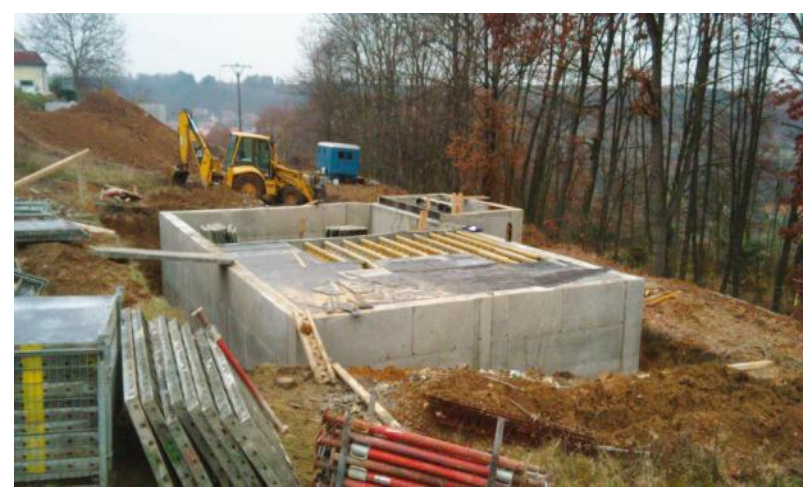

Figure 1. An example of an underground construction

Concrete construction is considered as water impermeable if it is able to resist water under pressure in such a way that no leakage or moist spots are visible on its air side. This feature is verified by testing the depth of the penetration of water under pressure according to ČSN EN 12390-8 [3] or by verification of water impermeability via the, HV" test according to the terms of TKP R RC ČR [4]. When selecting concrete components and preparing the concrete recipe, the required properties of fresh and dried concrete are considered. The selection of cement type should consider what environmental influences affect a concrete structure and the use of a massive or thin-walled structure. The parameters of aggregate, such as maximal grain size, granulometry, or grain shape, are equally important. Regarding volume changes, it is assumed that concrete is a three-phase composite material formed by a cement grout, an aggregate, and an interphase zone. The cement grout takes up approximately $24-30 \%$ of concrete volume. It consists of a cement binder, water, various types of additives and ingredients, air, and empty space. This whole part is subject to shrinkage. However, coarse and fine aggregate are considered as stable concrete volume [5]. Thus, aggregate is considered as a component that plays an important role in the shrinking resistance of the cement grout. [6] It was verified in experiments that a cement stone compresses the surface of an aggregate with a force in a radial direction at the beginning of concrete hardening. Thanks to capillary forces, the shrinkage of cement stone and compression of the aggregate surface occur. The inflexion point of this dependency more or less corresponds with the change of the elastic deformation to the permanent - plastic deformation. The concentration of tensile stress around aggregate grains (transit zone) occurs between materials with different properties, which can lead to concrete failure. That is why the adhesion between the cement grout and aggregate is important.

The relation of volume changes of concrete with different types of aggregate, respective of the different size of the maximal grain and granulometric curve, will be verified in this experiment. The key properties regarding the high water impermeability of white boxes, such as water absorption and the depth of penetration of water under pressure, will be verified in this experiment.

\section{Materials and Methods}

\subsection{Continuous and Discontinuous Granulometric Curve}

The main goal of this experiment was to verify the influence of various compositions of aggregates and the influence of a cement matrix on resulting properties such as the water absorption of concrete, the depth of water penetration, and volume changes, which are determined to ensure the high water impermeability of white boxes. In the first part of the experiment, recipes with a different type of aggregate were designed. The aggregate itself plays an important role during concrete shrinkage.

Some scientific studies show that for heterogeneous materials, such as concrete, failures most often occur in the weakest junction between the cement grout and aggregate, which is called the interphase zone. The concentration of tensile stress around the grains of aggregate (the transit zone) between materials with different properties can lead to concrete failure. For this reason, the adhesion between the cement grout and aggregate is important. Thus, the surface of an aggregate that affects the transit zone is an important factor. [7] For this experiment, two types of aggregate were used, namely crushed aggregate from Olbramovice and gravel from Žabčice. For both aggregates, recipes were designed with regard to using the continuous granulometric curve with the maximal grain of aggregate $\mathrm{D}_{\max } 16 \mathrm{~mm}$. Furthermore, recipes with a discontinuous granulometric curve, with the omission of fraction $4-8 \mathrm{~mm}$ and a maximal grain of aggregate $D_{\max } 22 \mathrm{~mm}$, was designed in addition to the previous recipes. The resulting granulometric curves of aggregates with $D_{\max } 16 \mathrm{~mm}$ and $D_{\max } 22 \mathrm{~mm}$ were identical in order to compare the influence of the aggregate type on the monitored concrete parameters. From the mineralogical point of view, the Olbramovice aggregate was granodiorite, and the Žabčice gravel was sedimentary psammite-type rock.

\subsection{Use of Finely Ground Limestone}

In the next part of the experiment, recipes with an additive of finely ground limestone were designed for this type of granulometric curve. The additive of finely ground limestone is widely considered as a non-active additive that does not actively influence the hydration process. It is used especially as a positive influence on the microstructure and improving the mechanical properties of a cement composite. However, some studies show the opposite and state that the presence of finely ground limestone slightly accelerates the hydration of cement (especially for clinker material $\mathrm{C}_{3} \mathrm{~S}$ ). The presence of limestone provides a more stable distribution of the pore size. This decreases the permeability of concrete and the transit zone between aggregate grains and improves the 
hydrated cement grout. If limestone grains are smaller than cement particles, pores between moisturising products fill up, which makes the cement matrix denser. [8-10] Some studies point out that if the dose of limestone is lower than $15-20 \%$, the workability of a mixture improves. At the same time, the compliance of appropriate fineness leads to a reduction of the concrete shrinkage.[11,12] In this case, finely ground limestone was used as an internal additive, and a chemical reaction during the hydration process is not expected from it. The reason for its use is primarily to reduce the cement matrix porosity. The compensation of cement by finely ground limestone was $17 \%$.

In total, it was designed eight concrete recipes with an assumed compressive strength of approximately $60 \mathrm{MPa}$ after 28 days. For all recipes, Portland cement CEM I 42,5 $\mathrm{R}$, Mokrá was used. The amount of water and plasticising admixture was designed by a slump test for the S4 class, approximately $170 \mathrm{~mm}$, to reach the consistency of fresh concrete. Thanks to identical consistency of all mixtures, it will be possible to monitor the influence of different aggregate types and granulometric curves, respective of the maximal aggregate grain, and also the impact of finely ground limestone on the resulting properties of the fresh and hardened concrete. For hardened concrete it will be monitored development of compressive strenght in age from 7 to 90 days. Another properties, which could predicate impermebility of the designed concrete are mainly the water absorption and the depth of penetration in age 7 till 90 days. Another monitored property that is closely associated with the water impermeability of concrete will be the assessment of the changes in concrete. The measurement of volume changes will start from the fresh stage, right after mixing, up to 28 days. The composition of all recipes are stated in Table 1 .

Table 1. Mix design

\begin{tabular}{|l|c|c|c|c|c|c|c|c|}
\hline & O16 & O22 & Z16 & Z22 & O_L16 & O_L22 & Z_L16 & Z_L22 \\
\hline CEM I 42, 5 R Mokrá [kg] & 435 & 435 & 435 & 435 & 390 & 390 & 390 & 390 \\
\hline Limestone & - & - & - & - & 80 & 80 & 80 & 80 \\
\hline DTK 0-4 mm Žabčice [\%] & 48.3 & 48.3 & 45.9 & 45.9 & 47.6 & 47.6 & 45.1 & 45.1 \\
\hline HTK 4-8 mm Žabčice [\%] & - & - & 13.3 & - & - & - & 13.6 & - \\
\hline HDK 4-8 mm Olbramovice [\%] & 11,3 & - & - & - & 11.7 & - & - & - \\
\hline HTK 8-16 mm Žabčice [\%] & - & - & 40.8 & 32.0 & - & - & 41.3 & 32.4 \\
\hline HDK 8-16 mm Olbramovice [\%] & 40.4 & 30.3 & - & - & 40.7 & 30.5 & - & - \\
\hline HTK 16-22 mm Žabčice [\%] & - & - & - & 22.1 & - & - & - & - \\
\hline HDK 11-22 mm Olbramovice [\%] & - & 21.4 & - & - & - & 21.9 & - & 22.5 \\
\hline MC Powerflow 2695 [kg] & 3.5 & 3.5 & 3.5 & 3.5 & 3.9 & 3.9 & 3.9 & 3.9 \\
\hline Water [kg] & 170 & 170 & 170 & 170 & 175 & 175 & 175 & 175 \\
\hline
\end{tabular}

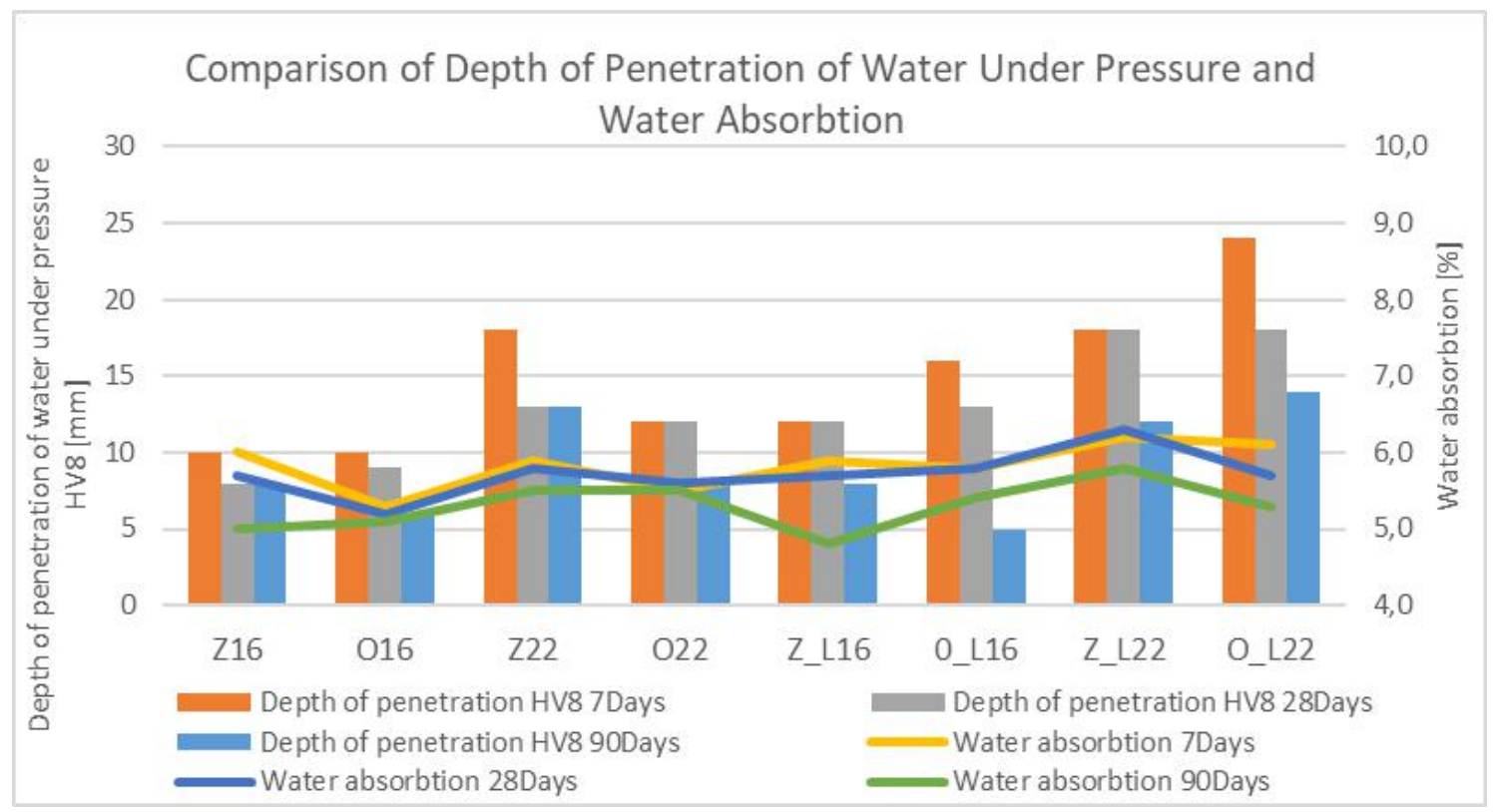

Figure 2. The determination of the depth of penetration of water under pressure and water absorption 


\section{Results}

\subsection{The Determination of Compressive Strength, the Depth of Penetration, and the Water Absorption of Concrete}

In the following part, the results of the monitored properties of designed recipes are summarised. Table 2 shows the results of compressive strength, water absorption, and the depth of penetration of water under pressure. Compressive strength was determined on cube-shaped bodies with an edge of $150 \mathrm{~mm}$ at the age of $7,28,90$. The determination of water absorption was performed following the CSN 73 1316[13] standard on specimens in the shape of a $150-\mathrm{mm}$ cube at 7, 28, and 90 days of age. The determination of the depth of penetration of water under pressure was performed on the water impermeability degree HV8 according to the methodology of TKP ĽVC ČR, where a specimen in the shape of a $150-\mathrm{mm}$ cube is exposed to water pressure of $400 \mathrm{kPa}$ for 24 hours and water pressure of $800 \mathrm{kPa}$ for the next 48 hours. This methodology was chosen to meet the stricter criteria for constructions with high requirements for water impermeability of concrete, such as the construction of white boxes. This determination was also verified at the age of 7-90 days.

\subsection{The Determination of Concrete Volume Changes}

Another important property for ensuring the high resistance of concrete against the impact of water, primarily with regard to cracks and subsequent absorption of moisture and water into the construction, are volume changes in the concrete. Although the shrinking process is related to the chemical reaction of cement and water, an aggregate as an internal material plays an important role in resisting the disproportionate shrinkage of the cement paste. During the process of cement stone hydration, there is a process of tensile stress around grain of aggregate (in transit zone), and this tensile stress could lead to failure of concrete. $[14,15]$ this is the reason why it is important adhesive connection between aggregate and cement paste. The impact of different aggregate types on concrete shrinkage is illustrated in Figure 3, and the exact shrinkage values are in $\mu \mathrm{m} / \mathrm{m}$ and shown in Table 3 .

Monitoring of the shrinking process was performed following the Austrian OENORM B 3329:2009-06-01 standard [16]. Shrinking troughs with a size of $60 \times 100 \times 1000 \mathrm{~mm}$ with a movable partition were used, and the connected sensor can monitor volume changes since the fresh concrete. The graphic progress of the shrinkage represents the arithmetic mean of three measurements.

Table 2. Summarised results of the depth of penetration of water, pressure, and water absorption

\begin{tabular}{|c|c|c|c|c|c|c|c|c|c|}
\hline & & 016 & $\mathbf{O 2 2}$ & Z16 & $\mathbf{Z 2 2}$ & O_L16 & O_L22 & Z_L16 & Z_L22 \\
\hline \multirow{3}{*}{ Compressive strength [MPa] } & 7 days & 57.3 & 60.4 & 52.0 & 56.4 & 60.0 & 57.8 & 52.6 & 52.8 \\
\hline & 28 days & 73.8 & 76.3 & 61.5 & 67.2 & 69.0 & 71.8 & 60.2 & 60.7 \\
\hline & 90 days & 76.2 & 79.3 & 63.2 & 68.1 & 77.5 & 78.8 & 63.7 & 68.0 \\
\hline \multirow{3}{*}{ The depth of water penetration HV8 [mm] } & 7 days & 10 & 10 & 18 & 12 & 12 & 16 & 18 & 24 \\
\hline & 28 days & 8 & 9 & 13 & 12 & 12 & 13 & 18 & 18 \\
\hline & 90 days & 8 & 6 & 13 & 8 & 8 & 5 & 12 & 14 \\
\hline \multirow{3}{*}{ Water absorption [\%] } & 7 days & 6.0 & 5.3 & 5.9 & 5.5 & 5.9 & 5.8 & 6.2 & 6.1 \\
\hline & 28 days & 5.7 & 5.2 & 5.8 & 5.6 & 5.7 & 5.8 & 6.3 & 5.7 \\
\hline & 90 days & 5.0 & 5.1 & 5.5 & 5.5 & 4.8 & 5.4 & 5.8 & 5.3 \\
\hline
\end{tabular}




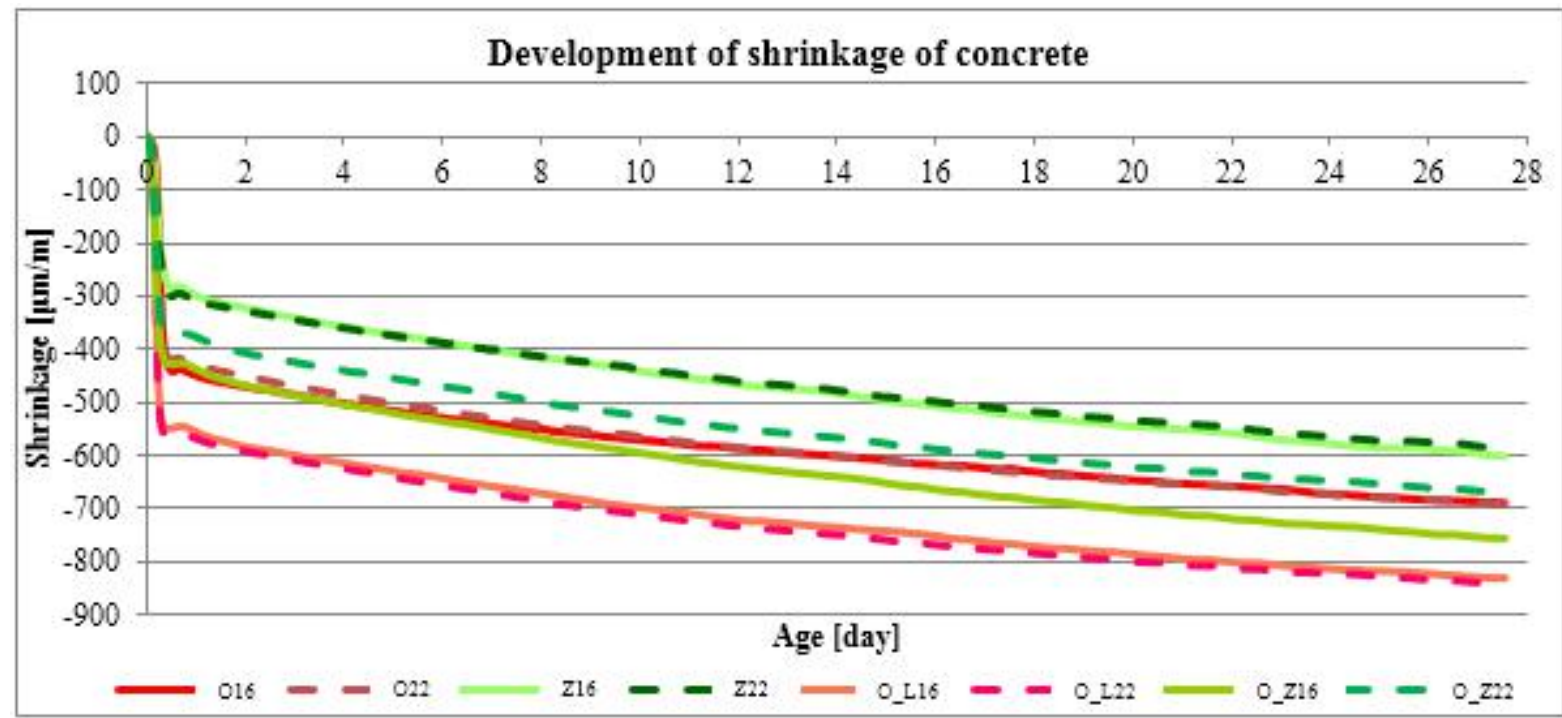

Figure 3. Graphic progress of volume changes

Table 3. Summarised results of volume changes

\begin{tabular}{|c|c|c|c|c|c|c|c|c|c|}
\hline \multicolumn{2}{|c|}{} & O16 & O22 & Z16 & Z22 & O_L16 & O_L22 & Z_L16 & Z_L22 \\
\hline \multirow{3}{*}{ Shrinkage $[\boldsymbol{\mu m}]$} & $1^{\text {st }}$ day & 449 & 429 & 298 & 308 & 555 & 568 & 437 & 376 \\
\cline { 2 - 11 } & $7^{\text {th }}$ day & 540 & 530 & 401 & 402 & 658 & 671 & 551 & 484 \\
\cline { 2 - 11 }$y$ & $28^{\text {th }}$ day & 693 & 694 & 605 & 590 & 835 & 842 & 756 & 669 \\
\hline
\end{tabular}

\section{Discussion}

The determined compressive strength for all recipes shows significant dissimilarity between the types of aggregate. Within the designed recipes, a constant dose of binding agents was used for both types of concrete to monitor only the direct impact of the aggregate type, eventually limestone as an additive, on monitored parameters, primarily on volumetrics changes of concrete. Thanks to that, it was unequivocally proven that recipes with quality crushed aggregate reached noticeably higher compressive strength. However, the requirements of a minimum of $60 \mathrm{MPa}$ after the 28-day-long standard load was reached for all recipes.

The results of the determination of the depth of penetration of water under pressure show higher levels of water impermeability for concretes using the crushed aggregate from Olbramovice, with which the lowest water absorption in depths of $5 \mathrm{~mm}$ and $6 \mathrm{~mm}$ was reached after 90 days. In general, the values of the depths of penetration decreased with the age of the samples for all recipes. When using the gravel from Žabčice, lower levels of water impermeability were achieved. According to the observed values, it can be said that the requirement of a maximal penetration of $60 \mathrm{~mm}$ stated in TKP $\check{\mathrm{R} V C} \check{C} \mathrm{R}$ is met for all cases. When comparing the continuous granulometric curve with the discontinuous granulometric curve, the values of the depth of penetration of water are almost identical. A similar trend is obvious in the results of the water absorption where the lower levels were reached with crushed aggregate, compared to the gravel. However, these facts are most likely related to the properties of the aggregates. The psammite-type gravel of Žabčice shows higher water absorption than crushed granodiorite aggregate from Olbramovice.

The results of the experiment unequivocally prove that the dissimilarity of granulometric curves (continuous and discontinuous) and different $\mathrm{D}_{\max }$ does not have an impact on the water absorption of concrete.

The partial replacement of cement by finely ground limestone does not confirm the assumption of ensuring the lower porosity of a cement matrix and the results show higher water absorption, as well as deeper penetration of water under pressure. The results of the determination of volume changes point out the importance of the measurement of this process in the fresh mixture when the biggest portion (approximately $50 \%$ ) of overall shrinkage occurred during the first day of concrete hardening. From the results of this experiment, we can unequivocally state that when using finely ground limestone, the level of shrinkage was higher in comparison with the mixture where no additive was used. Based on the acquired results, 
it is possible to say that the high fineness of limestone obviously leads to a bigger specific surface of the whole binding agent of the composite and during the reducing of the relative humidity of the sample, caused by the hardening, the mutual attraction of particles occurs, therefore, the volume changes are bigger.

The shrinkage values showed smaller volume changes when the Žabčice gravel was used. From the perspective of designing concrete mixtures with small volume changes, this knowledge seems very important. The result of the experiment is in partial conflict with the general theory in which crushed aggregate is considered as more suitable for production of these concrete types. General theories regarding concrete are based on the assumption that the bigger specific surface a crushed aggregate has will create a more positive impact on its incorporation into the cement matrix (the transit zone) and the aggregate will be more resistant to volume changes thanks to the unevenness of its grains. However, the result of the experiment proves that the water stuck on the surface of crushed aggregate grains most likely causes higher porosity of the transit zone, which leads to a higher shrinkage value of the whole composite. The surface of an almost regular round surface gravel catches little water, and so the transit zone is not affected by this water.

The impact of the maximal grain of the aggregate and discontinuous granulometric curve was not proven, and mixtures with identical types of aggregate show identical shrinking values at different curves. This result is positive especially for using the continuous granulometric curve, which is used more in practice thanks to its positive impact on some other mechanic parameters of concrete. The results of the performed experiment also point out the improvement of the strength parameters at the continuous granulometric curve with $D_{\max } 22 \mathrm{~mm}$. This fact is connected to the statement that it is possible and appropriate to use higher $\mathrm{D}_{\max }$.

\section{Conclusions}

This article deals with experimental research on the impact of different aggregate types and its composition on resulting concrete properties representing the water impermeability level of concrete for the construction of white boxes. Furthermore, this experiment verified the impact of finely ground limestone on the monitored parameters. During the design of the concrete mixtures, the use of a high amount of binding agent that is also used for ensuring the higher compactness of cement stone was considered. For all mixtures, identical consistency was ensured, so it was possible to evaluate the impact of different aggregate types, the maximum grain of the aggregate and finely ground limestone.

According to the obtained results, it was shown the unequivocal influence of various types of aggregate on the resulting compressive strength in all ages. When crushed aggregates were used, higher compressive strengths were achieved in all cases. From the results of the volume changes, the unequivocal impact of finely ground limestone is obvious when the negative impact on the resulting shrinkage was observed for all aggregate compositions. Moreover, the difference between gravel and crushed aggregate was observed, whereas significantly lower levels of shrinkage were achieved for gravel, both on the first day and day 28. The relation of volume changes and the depth of penetration of water and water absorption of different aggregate types was not clearly proven in this case. However, the resulting values of the performed experiments prove that it is possible to use both types of aggregates, and also continuous and discontinuous granulometric curves in the construction of white boxes. From the perspective of strength characteristics, the discontinuous granulometric curve with $D_{\max } 22 \mathrm{~mm}$ and the use of crushed aggregates seems to be more suitable.

\section{Acknowledgments}

This paper has been worked out under the project $\mathrm{nb}$. FAST-J-19-6065 „Design of concrete for „white boxes" with optimized dosing of fine components and regarding to reduction of concrete volumetric changes.".

\section{REFERENCES}

[1] In Czech: Realizace betonové konstrukce bílé vany. Asb-portal.cz: Stavebnictví. Online available fromhttps://www.asb-portal.cz

[2] In Czech: R. Coufal, J. L. Vítek, K. Chmelíková. TECHNOLOGIE BETONU PRO VODONEPROPUSTNÉ KONSTRUKCE - BÍLÉ VANY, Beton TKS, Praha, 2015, 15(2), 12-17, ISSN 1213-3116.

[3] EN $12390-8$. Testing hardened concrete - Part 8: Depth of penetration of water under pressure. 2009

[4] In Czech: Stanovení vodotěsnosti betonu. Podle ǨVC TKP kapitola 1, Praha, 2009

[5] S. Tangtermsirikul, S. Satong. Modeling of Aggregate Stiffness and Its Effect on Shrinkage of Concrete. RESEARCH ARTICLE. 2001, Pages 185-192 Online available from http://www.scienceasia.org/

[6] H. Beushausen, T. Dittmer. The influence of aggregate type on the strength and elastic modulus of high strength concrete. Construction and Building Materials. 2015, (Volume 74), Pages 132-139 Online available from: https://www-sciencedirect-com

[7] H.CH. Byoung, H.N. Boo, S. Sangyeon, K. Jungil, A. Jinwoo , Y. Heejung. Waterproofing performance of waterstop with adhesive bonding used at joints of 
underground concrete structures, Construction and Building Materials, Volume 221, 2019, Pages 491-500, ISSN 0950-0618, Online available from https://www.sciencedirect.com

[8] T. Proske, M. Rezavani, S. PALM, Ch. Müller, C. A. Graubner. Concretes made of efficient multi-composite cements with slag and limestone. 2018, (Volume 89), Pages 107-119 Online available from https://www-sciencedirect-com

[9] M. Rezvani, T. Proske. Influence of chemical-mineralogical properties of limestone on the shrinkage behaviour of cement paste and concrete made of limestone-rich cements. Construction and Building Materials. 2017, (Volume 157), Pages 818-828 Online available from: https://www-sciencedirect-com

[10] S. Palm, T. Proske, M. Rezvani, S. Hainer, Ch. Müller, C.A. Graubner. Cements with a high limestone content Mechanical properties, durability and ecological characteristics of the concrete. Construction and Building Materials. 2016, (Volume 119), Pages 308-318 Online available from https://www-sciencedirect-com

[11] G.K. MOIR, S. KELHAM. Developments in the manufacture and use of Portland limestone cemen. 1997, (Volume 172), Pages 797-820 Online available from https://www.scopus.com

[12] M.S. MEDDAH, M.C. LMBACHIYA. Potential use of binary and composite limestone cements in concrete production. Construction and Building Materials. 2014, (Volume 58), Pages 193-205. Online available from https://www-sciencedirect-com

[13] In Czech: ČSN 731316 Stanovení vlhkosti, nasákavosti a vzlínavosti betonu. Praha, UNMZ. 1990

[14] T. Fujiwara. Effect of Aggregate on Drying Shrinkage of Concrete. Journal of Advanced Concrete Technology - J ADV CONCR TECHNOL. 6. 31-44. 10.3151/jact.6.31.

[15] Ihab ADAM, Kenji SAKATA, Toshiki AYANO. Influence of Coarse Aggregate on the Shrinkage of Normal and High-Strength Concretes. Journal of the Faculty of environmental Science and Technology. Okayama University, Vol. 6, No. 1.pp. 41-45. 2001

[16] OENORM B 3329: 2009 - 06 - 01. Grout - Requirements and test methods. Austria, 2009. 